\title{
Development Land Erosion Model Using Model Builder GIS (Case Study: Citepus Watershed)
}

\author{
Dina PA Hidayat ${ }^{1, *}$, Sih Andajani ${ }^{2}$ \\ ${ }^{1}$ Laboratorium Keairan, Faculty of Civil Engineering and Planning, Trisakti University, Jakarta, Indonesia \\ ${ }^{2}$ Laboratorium Keairan, Faculty of Civil Engineering and Planning, Trisakti University, Jakarta, .Indonesia
}

\begin{abstract}
Land erosion is the impact of increasing runoff discharge and land use conversion to impervious areas. Land erosion usually calculated by formula called USLE (Universal Soil Loss Equation) then modified as MUSLE (Modified Universal Soil Loss Equation). These formula calculate average annual soil loss in tons/areas depends on rainfall erosivity (R), soil erodibility factor (K), topographic factor (LS), cropping and conservation factor (CP). GIS (Geographic Information System) is a system designed to capture, manipulate, and analyze spatial/geographic data. There are some tools related water resources analysis in ArcGIS such as: watershed analysis and also have a tools for user to create their own model called model builder. This research was aim to create a model to calculate land erosion using MUSLE formula by model builder in ArcGIS. The output for this research is the model which can be used to calculate annual soil loss in watershed area based on GIS systems. For the model trial and case study, we use Citepus watershed located on Bandung West Java, that has 5 river branches: Cibogo, Cikakak, Cilimus, Cipedes and Ciroyom. As the result of the model, the value of average annual soil loss in Citepus watershed can be calculated automatically by developed model.
\end{abstract}

\section{Introduction}

\subsection{Background}

The erosion process of soil particle on the surface watershed usually called land erosion. Sediment discharge which is resulted by land erosion is the one of sediment input in the river beside bank erosion. As a result of runoff from rainfall, soil particles on the surface of a watershed can be eroded and transported through the processes of sheet, rill, and gully erosion. Once eroded, sediment particles are transported through a river system and are eventually deposited in reservoirs, in lakes, or at sea.

Soil erosion is a serious problem from agricultural intensification, land degradation and other anthropogenic activities. Assessment of soil erosion is useful in planning and conservation works in a watershed or basin [1] Beside that, flood and inundation are getting more complex especially in urban areas, and it can be worst by water pollution. Flood and inundation has occurred because of incapability of drainage channel/river to collect runoff flow. This lack of capacity can caused by sedimentation in river bank/drainage channel, that sourced by land erosion.

Since the last century, soil erosion accelerated by human activities has become a serious environmental problem. Soil erosion risk varies from case to case depending on the configuration of the watershed (topography, shape), the soil characteristics, the local climatic conditions and the land use and management practices implemented [2].

Because of the risk of soil erosion, the estimation of soil erosion rate is very important to predict the value of annual soil erosion in a watershed. After soil erosion is predicted, this information is needed to provide prerequisite information for effective watershed management, including soil conservation strategies. Appropriate watershed management plans for sustainable development need reliable long-term soil loss information at various parts of the watershed [3].

Soil erosion prediction technology began over 70 years ago when Austin Zingg published a relationship between soil erosion (by water) and land slope and length,followed shortly by a relationship by Dwight Smith that expanded this equation to include conservation practices [4]. The general equation of land erosion is Universal Soil Loss Equation (USLE) (Wischmeier and Smith, 1965). This equation is the multiplication of rainfall factor, soil erodibility factor, topography factor, cropping management factor and erosion control factor. There are continued research of land erosion equation such as: Revised Universal Soil Loss Equation (RUSLE) (Wischmeier and Smith, 1978) and Modified Universal Soil Loss Equation (MUSLE) (Williams, 1975).

In the last decade, good amount of work has been done on soil erosion assessment in large catchments and at a regional scale by using lumped approaches and very few

\footnotetext{
* Corresponding author: dinaparamitha06@gmail.com or dina.hidayat@trisakti.ac.id
} 
on micro-units and gridcell basis [3]. Today, GIS (Geographical Information Systems) has been used for engineering field, and many research used GIS for predict/estimate soil erosion on watershed.

This research aim to calculate soil annual loss rate by MUSLE equation and GIS application. GIS application on this research are generating Citepus watershed, MUSLE factor calculation and developing annual soil loss model by model builder GIS.

This research use Citepus watershed as the case study, located on Bandung, West Java, Indonesia ( $7^{\circ} 52^{\prime} 15^{\prime \prime}$ $7^{\circ} 57^{\prime} 50^{\prime \prime} \mathrm{S}$ and $\left.107^{\circ} 34^{\prime} 15^{\prime \prime}-107^{\circ} 36^{\prime} 45^{\prime \prime} \mathrm{C}\right)$. The catchment area of Citepus watershed is 1820 ha, consist of 8 sub district (Sukasari, Sukajadi, Cicendo, Andir, Bojongloa Kidul, Astana Anyar and Bojongloa Kaler). The Citepus watershed has elevation between 670 meters until 950 meters above sea level and different slope between north and south area. In the north area of Citepus watershed, it is steep area, has $7 \%$ slope. On the other hand, the middle and south area of Citepus watershed is relatively flat area, has $0-6 \%$ slope. Rainy season dominates this area with average daily precipitation for 10 years (1997-2007) of $95 \mathrm{~mm}$ and large variation for each year. Citepus River is one of the main river, flow to Citarum River, has $10 \mathrm{~km}$ of length and 5 river branches (Ciroyom,Cikakak,Cilimus,Cibogo and Cipedes).

One of factor that cause flood in Bandung is sedimentation at the section of the river. Sedimentation cause the less of river capacity for retaining stream discharge. The area is covered by housing area $76 \%$, funeral area $1 \%$, green area $2 \%$, rice field $1 \%$ and others $21 \%$. Furthermore, less of river capacity can cause overtopping in some location of Citepus river section, such as: overtopping in Pagarsih street section that has 5 hours duration and 0.8 ha flooding area. As a result of identification at the section, there is sediment stack that causes river width changing from 12 meters to 6 meters.

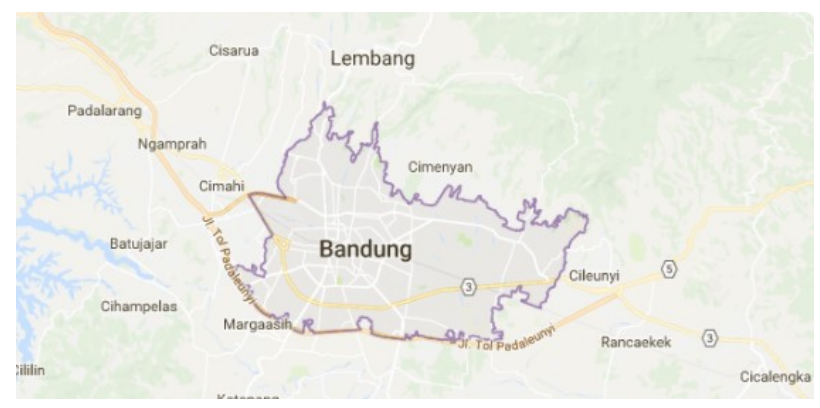

Fig. 1. Map of Location Study (maps.google.com)

\subsection{Objectives}

This research is aim to: develop MUSLE equation model with model builder GIS and calculate soil annual loss for Citepus watershed by developed model.

\subsection{Scope}

This research located in Citepus Watershed with Citepus River as the main river that has 5 branch (Cilimus, Cikakak, Cibogo, Ciroyom and Cipedes). GIS for this research is used for watershed boundary analysis, MUSLE factor analysis and develop MUSLE equation with model builder GIS

\section{Materials and Method}

\subsection{Methodology}

This research was done by following step:

\section{a. Data collection}

Raw data was collected consist of: hydrology data, land use, topography, conservation data,etc. All data sourced from related government agency (such as: bakosurtanal, Ministry of Public Works), books, journal, paper and related project.

Hydrology Data

Hydrology data was used for estimate rainfall erosivity factor. This research used Cemara station as the sources of rainfall data.

Topography Map

Digital Elevation Model (DEM) is one of the important parameters for soil erosion assessment. Notable uncertainties are observed in this study while using three high resolution open source DEMs [5]. For topography data, this research used SRTM with open source download facility.

\section{b. MUSLE factor mapping on GIS}

For this research, GIS use for generate watershed boundary and analyze MUSLE factor (soil erodibility, topography factor and cropping factor). Watershed boundary was generating by watershed menu on GIS toolbox, with SRTM (Shuttle Radar Topography Mission) as the input.

\section{c. Develop MUSLE equation using Model Builder GIS}

After all factor was generated, develop land erosion model for calculating soil loss annual rate using Model Builder GIS. The model can be used for another case, not only for Citepus watershed.

d. Calculate annual soil erosion rate by developed model and classify erosion rate

After model was generated on model builder GIS, try to running the model for Citepus Watershed data, then classify Citepus erosion rate by following table (Wiharta et al,1997).

Table 1. Erosion Rate Classification

\begin{tabular}{|c|c|}
\hline $\begin{array}{c}\text { Annual Soil Loss Rate } \\
\text { (Tons/ha/yr) }\end{array}$ & Erosion Rate Classification \\
\hline $0-15$ & Very Light \\
\hline $15-60$ & Light \\
\hline $60-180$ & Medium \\
\hline $180-480$ & Heavy \\
\hline$>480$ & Very Heavy \\
\hline
\end{tabular}




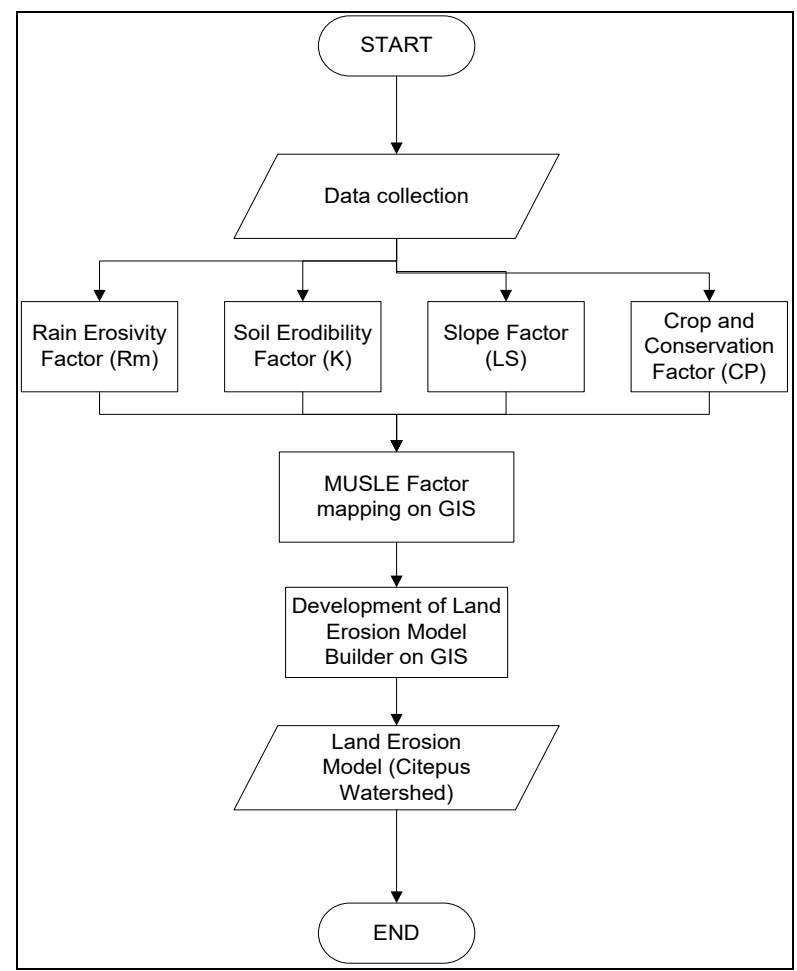

Fig. 1. Research Flowchart

\subsection{Land Erosion Modelling}

Soil erosion is an important item for consideration in the planning of watershed development works. It reduces not only the storage capacity of the downstream reservoirs but also deteriorates the productivity of the watershed. Erosion involves the detachment, transport and deposition of soil particles and aggregates. Among available soil erosion and sediment yield models, the universal soil loss equation (USLE), the revised version, Revised universal soil loss equation (RUSLE), and its modified version (MUSLE) are widely used in hydrology and environmental engineering for computing the potential soil erosion and sediment yield [6].

Modified Universal Soil Loss Equation (MUSLE) is an empirical model, which gives average soil loss produced by rainfall events (Williams, 1975). This equation used runoff energy, soil erodibility, slope length and steepness vegetative cover and management practices as factors. MUSLE (Modified USLE) equation was developed using rainfall erosivity factor as the different factor than USLE.

$$
A=R x K x \operatorname{LS} x C \times P
$$

A = long term average annual soil loss, ton/acre/year, ton/ha/year

$\mathrm{Rm}=$ rainfall erosivity

$\mathrm{K}=$ soil erodibility

$\mathrm{LS}=$ topography factor

$\mathrm{C}, \mathrm{P}=$ cropping and conservation factor

The rainfall erosivity factor was developed by Williams dan Berndt (1977), consist of runoff volume and peak discharge. Peak discharge is calculated using rasional equation which assume that rainfall has uniform intensity on entire watershed.

$$
R=11,8(Q v \times Q p)^{0,56}
$$

$\mathrm{Qv}=$ runoff volume $\left(\mathrm{m}^{3}\right)$

$\mathrm{Qp}=$ peak discharge $\left(\mathrm{m}^{3} / \mathrm{sec}\right)$

For the model accuracy, MUSLE increases sediment yield prediction accuracy and as well as it eliminates the need for delivery ratios [6]. The MUSLE equation has been used previously by many researchers (Tripathi et al. 2001) and, in some cases, the equation was subjected to different modifications. The sediment yield model like MUSLE is easier to apply because the output data for this model can be determined at the watershed outlet (Pandey et al. 2009)

\subsection{GIS Application and Model Builder}

Geographic Information System is a tools to analyze, visualize and interpret data with spatial and geographic data. Nowadays, many research on engineering field especially on water resources engineering using GIS as a tools. There are several menu/tools that helped us to analyze water resources data, such as: thiessen polygon, watershed generating menu, etc. For soil erosion estimation, LWIS is one of tools that can be used. LWIS (the Integrated Land and Water Information System) is a a GIS software package from the International Institute for Geo-Information Science and Earth Observation in the Netherlands, has moved from paid (100 euros) proprietary status to free open source status as of today [11].

Based on Chandramohan (2015), ILWIS (Integrated Land and Water Information System) GIS was used to estimate MUSLE parameters and average soil loss. The topo-sheets were geo-referenced and base maps of watershed boundary, contours and drainage were generated. Different thematic maps, such as land use map, soil map, etc were prepared using the base maps and the data collected from field work. The digitized contour and spot height information were used to obtain the DEM (Digital Elevation Model) with the help of various interpolation routines available in ILWIS. This DEM was used for the creation of slope map.

Beside ILWIS, ArcGIS support user to make their own model with a tools called model builder GIS. Model Builder is a visual programming language for building geoprocessing workflows. Geoprocessing models automate and document your spatial analysis and data management processes.

Model Builder in ArcGIS support us to: Build a model by adding geoprocessing tools, map layers, datasets, and other data types, and connecting them to a process; Iteratively process every feature class, raster, file, or table in a workspace; Visualize your workflow sequence as an easy-to-understand diagram; Run a model step-by-step, up to a selected step, or run the entire model; Make model into a geoprocessing tool that can be shared with others or can be used in Python scripting and other models [10]. By 
model builder GIS, we can explore our creativity to make own model and developed model can be used for another case.

In fact, models have been more heavily influenced by their use in participatory contexts where visualization is of course important but where the predominant mode is to simply pick and choose from available software and engage in a loose coupling wherever such a coupling is required [9]. Several studies showed the potential utility of GIS technique for quantitatively assessing soil erosion hazard based on various models [2].

There are several research that used GIS for estimating soil erosion, such as:

a. GIS has been used to estimate soil loss in the Nethravathi Basin located in the southwestern part of India. Soil erosion in India has a major effect on the agricultural sector, siltation of reservoirs, degradation of soils, etc. in the nation (Ganashri,2016)

b. GIS environment used to create soil erosion maps of the specific years using data from meteorological stations, soil surveys, topographic maps, landsat satellite images in Jordan. Jordan is dominated by arid ecosystems that are vulnerable to human interventions and activities. It receives little rainfall with high intensity, which renders land degradation, soil erosion and desertification imminent threats of the ecosystem balance. Several changes in land cover have also occurred during the last decades (Minwer,2013)

c. GIS has been used to visualized the process of the dynamical change of water level in Nam Co Lake and dynamically demonstrate the evolution situation of Nam Co lake water level in three-dimensional space (Liu Bing,2011)

\section{Result and Discussion}

\subsection{Watershed Boundary Analysis}

Based on Mondal (2017), there is a significant variation in the rate of soil erosion only by using different DEMs of the same resolution and then by aggregating the resolution of all DEMs. the SRTM DEM performs better than the ASTER and the CARTOSAT DEMs in assessing the accuracy. With the increased resolution also, SRTM shows better performance.

Watershed boundary analysis was done by 2 step: cropping SRTM topography map using Mapper and watershed boundary analysis using ArcGIS 10.0. Cropping topography map using watershed coordinates as the boundary. The result can be seen on Fig. 3 .

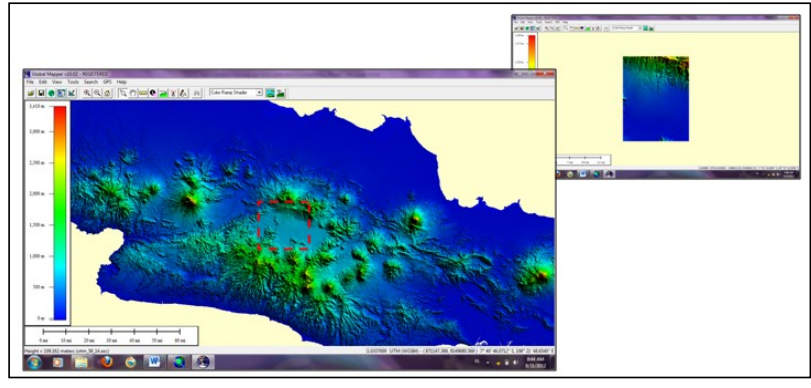

Fig. 2. Cropping Location Study

The cropped map was used for analyzing watershed boundary in ArcGIS 10.0. Firstly, analyze stream pattern and find Citepus river by using flow accumulation and flow direction menu. Citepus river location can be seen on Fig. 4. The next step is analyze the watershed boundary with determining the outlet point of watershed and subwatershed. The outlet point was determined on the downstream of Citepus River and for sub watershed was determined on the downstream of each river branch. The Citepus watershed and 5 sub watershed can be seen on Fig. 5.

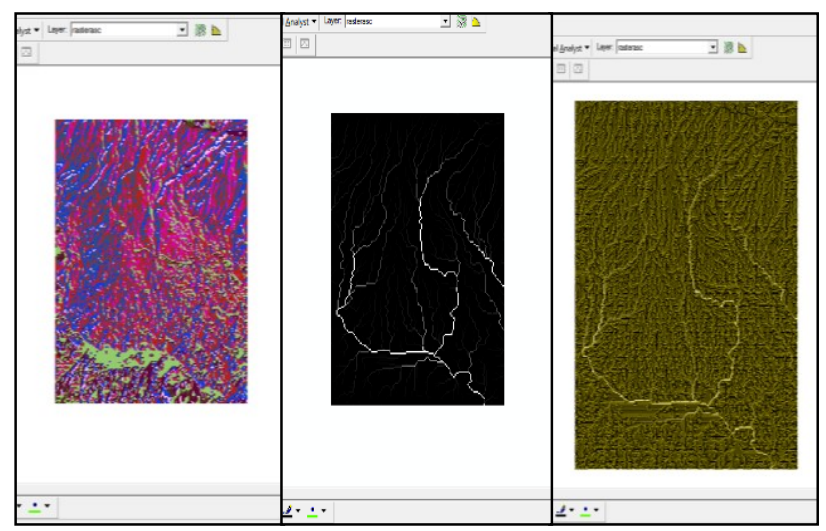

Fig. 4. Watershed Generating Process on GIS

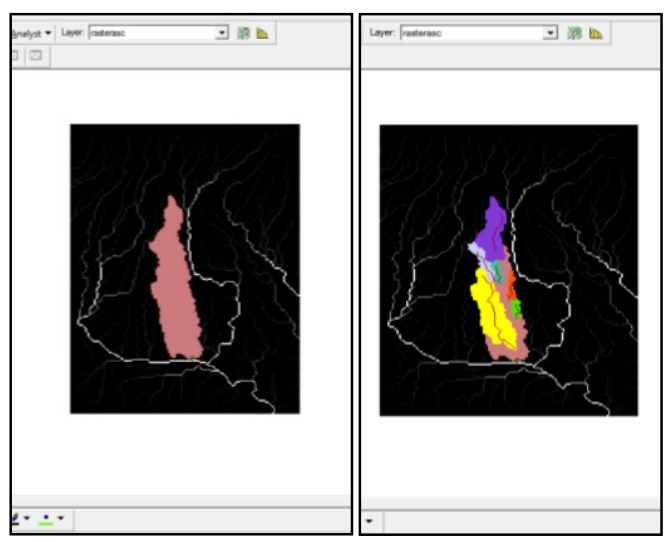

Fig. 3. Citepus Watershed and Sub Watershed on GIS 


\subsection{MUSLE factor calculation result}

Before generate the model using model builder, the average value of MUSLE factor (such as: cropping factor, topography factor and soil erodibility factor) for each sub watershed was determined by percentage of areas. Percentage of areas can be estimated by calculate areas on GIS attribute. Soil erodibility, cropping factor and topography factor of Citepus watershed seen on Fig. 6.

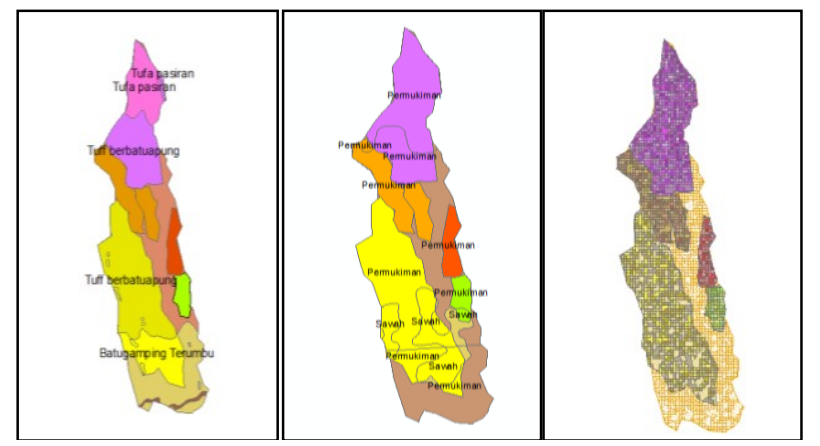

Fig. 4. MUSLE factor on GIS

The annual soil loss rate was calculated for each sub watershed using developed model. The model was developed by model builder GIS and raster calculation menu consist of multiplication of MUSLE factors. This model can be used for another study case/location by saving model file in arctoolbox format (Fig. 7). Developed model by model builder is quite easy to rerunning for another case/location, by copying model toolbox file and attached related layers on the new file. Model builder is quite simple to develop a model and it has varying command/menu that can be used.

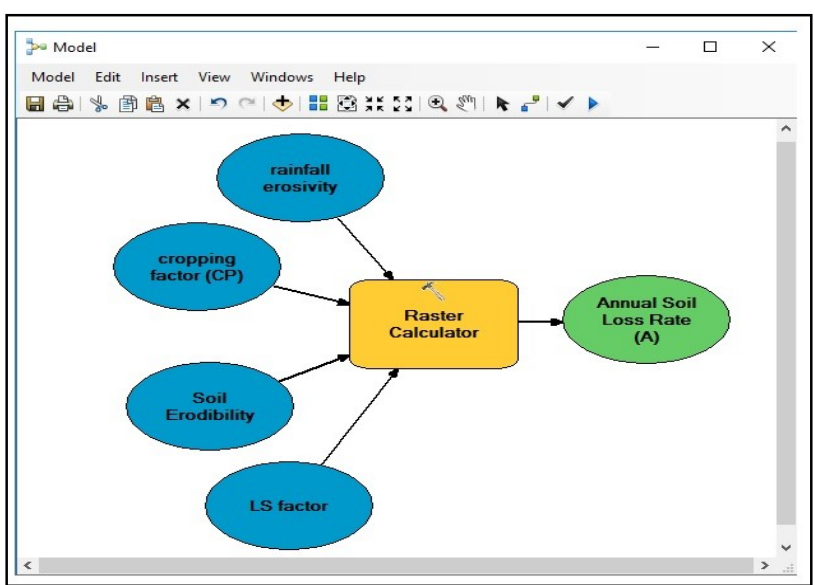

Fig. 5. MUSLE Soil Loss Model on Model Builder GIS

By using developed model, the annual soil loss can be calculated for each sub watershed. The calculation result can be seen on Table 2. From 5 sub watershed, Cilimus has the biggest value of annual soil loss rate (230 tons/ha/yr), while the smallest value is Ciroyom (129 tons/ha/yr). After MUSLE calculation, the next process was classify erosion rate by Table 1 as reference, and the result can be seen on Table 3. From 5 sub watershed, erosion rate result varying from medium to heavy classification. MUSLE calculation usually compared with sediment measured data for calibration. For Citepus watershed, there are no available sediment data that can be used for calibration because in Indonesia, small watershed such as Citepus usually doesn't have sediment measured station.

Table 2. Annual Soil Loss Result Calculation

\begin{tabular}{|c|c|c|c|c|c|c|}
\hline \multirow{3}{*}{$\begin{array}{c}\text { Sub } \\
\text { Watershed }\end{array}$} & \multicolumn{5}{|c|}{ MUSLE Factor Calculation } & $\begin{array}{c}\text { Annual } \\
\text { Soil Loss } \\
\text { Rate }\end{array}$ \\
\cline { 2 - 7 } & $\mathrm{R}$ & $\mathrm{C}$ & $\mathrm{P}$ & $\mathrm{LS}$ & $\mathrm{K}$ & $\mathrm{A}$ \\
\cline { 2 - 7 } & & & & & & tons/ha/yr \\
\hline Cibogo & 827 & 0.637 & 1 & 4.6 & 0.09 & 218 \\
\hline Cikakak & 947 & 0.53 & 1 & 3.5 & 0.09 & 158 \\
\hline Cilimus & 1048 & 0.637 & 1 & 3.9 & 0.09 & 234 \\
\hline Cipedes & 601 & 0.637 & 1 & 6.1 & 0.09 & 210 \\
\hline Ciroyom & 653 & 0.48 & 1 & 3.5 & 0.13 & 143 \\
\hline
\end{tabular}

Table 3. Erosion Rate Classification

\begin{tabular}{|c|c|c|}
\hline $\begin{array}{c}\text { Sub } \\
\text { Watershed }\end{array}$ & $\begin{array}{c}\text { Annual Soil Loss } \\
\text { Rate }\end{array}$ & $\begin{array}{c}\text { Erosion Rate } \\
\text { Classification }\end{array}$ \\
\cline { 2 - 3 } & tons/ha/yr & \\
\hline Cibogo & 218 & Heavy \\
\hline Cikakak & 158 & Medium \\
\hline Cilimus & 234 & Heavy \\
\hline Cipedes & 210 & Heavy \\
\hline Ciroyom & 143 & Medium \\
\hline
\end{tabular}

\section{Conclusion and Recommendation}

From this research, it can be conlude that Cilimus sub watershed has the biggest value of annual soil loss rate (234 ton/ha/yr), while the smallest value is Ciroyom (143 ton/ha/yr). All Citepus sub watershed (Cibogo, Cikakak, Cilimus,Cipedes and Ciroyom) have serious problem in land erosion (with erosion rate classification mediumheavy). This problem must be handled as soon as possible, by technical management (implementation of ecodrain concept, such as: land conservation) and non technical managemet (regulation implementation, community participation,etc). Developed model by model builder is quite easy to rerunning for another case/location. Model builder is quite simple and has varying command/menu that can be used.

\section{References}

1. B.P. Ganasri, H. Ramesh, Geoscience Frontiers 7, 953 - 961 (2016)

2. M.M. Alkharabsheh, T.K. Alexandridis, G. Bilas, N. Misopolinos, N. Silleos, Procedia Environmental Sciences 19, 912 - 921 (2013) 
3. G. Singh, R.K. Panda, International Soil and Water Conservation Research 5, 202 - 211 (2017)

4. J.M. Laflen, D.C. Flanagan, International Soil and Water Conservation Research 1, 1 - 11 (2013)

5. A. Mondal, D. Khare, S. Kundu, S. Mukherjee, A. Mukhopadhyay, S. Mondal, Geoscience Frontiers 8, 425 - 436 (2017)

6. P.S. Kumar, T.V. Praveen, M.A. Prasad, Aquatic Procedia 4, 1291 - 1298 (2015)

7. T. Chandramohan, B. Venkatesh, A.N. Balchand, Aquatic Procedia 4, 1227 - 1234 (2015)

8. L. Bing, J. Yao, Q. Liqing, Procedia Environmental Sciences 10, 1513 - 1518 (2011)

9. M. Batty, Procedia Social and Behavioral Sciences 21, 10 - 17 (2011)

10. http://pro.arcgis.com/en/proapp/help/analysis/geopr ocessing/modelbuilder/what-is-modelbuilder-.htm

11. http://freegeographytools.com/

12. http:// maps.google.com 